\title{
Research on the Reform of Computer Education and Teaching Mode Based on Data Mining
}

\author{
Wang Peiyi \\ Zhengzhou Infant Normal school, Zhengzhou, Henan, China, 450000
}

Keywords: computer education and teaching mode; data mining; reform

\begin{abstract}
Data mining as a cross-discipline, it promotes people's application of data from low-level simple queries to mining data from data and provides decision support. The reform of computer education teaching model based on data mining can help teachers provide effective guidance and decision-making information, and provide powerful data support for students' development. This paper analyzes in detail the existing computer education and teaching modes, and the application of data mining in computer education and teaching mode.
\end{abstract}

\section{Introduction}

With the rapid development of computer science and technology, computer education has also been rapidly developed. In order to adapt to the rapid development of the internet big data era, the reform of the computer education and teaching model has received increasing attention. The advent of the era of big data has brought us sufficient data sources. As the core technology of big data, data mining is to discover hidden and unknown data from a large amount of data that may be of interest to users and have potential value to the decision [1]. The usage of data mining technology to discover useful information and hidden laws from large amounts of data could help to provide guidance for computer education. Applying data mining to the reform of the computer education model and using new methods to solve the problems existing in the computer's existing education and teaching model is in conformity with the requirements of the times. Therefore, the research of computer education model based on data mining is to explore new teaching methods and establish corresponding teaching ideas and teaching models. The data resource processing platform for data mining of computer basic courses is as shown in Figure 1 blow.

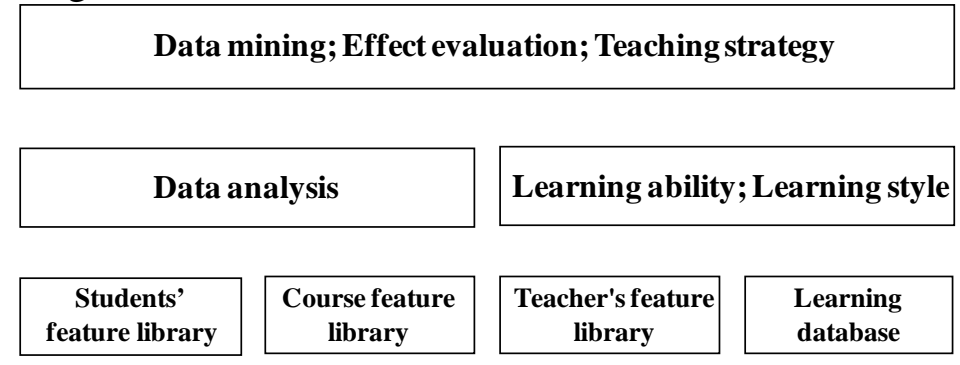

Fig.1 Application framework of data mining in computer courses

\section{The Status Quo of Computer Education and Teaching Mode}

\subsection{Instructive mode}

In the process of computer education and teaching, the application of lecture-based teaching mode is very common. At present, the most commonly used teaching in computer teaching is the lecture-based education mode, the teaching platform is based on the classroom teaching, and the majority of the computer professional teachers generally adopt this teaching mode. However, judging from the effect of this education and teaching mode, the teaching of computer-based teaching 
methods lacks binding force on students, which lead to the low participation awareness of the students, and the teaching scene of higher authenticity is not created, making it makes it difficult to achieve good results in this kind of education and teaching mode.

\subsection{Collaborative mode}

The use of collaborative computer education and teaching mode requires students to fully interact with their classmates or teachers on the teaching platform, so that students will be able to embody their self-value while receiving computer professional education, thereby improving the quality of learning [2]. From the teaching point of view, to make the collaborative computer education and teaching mode could fully play its role, it is necessary to create a good teaching environment, that is, the hardware equipment can meet the teaching needs, having a good resource environment, and the training of students be based the perspective of student personality. Guiding students in learning to use various resources and use collaborative methods to solve problems. And with the enhancement of student collaboration, the effectiveness of computer education and teaching will also increase.

\subsection{Discussion mode}

The implementation of a discussion-type computer education and teaching model is that teaching content revolves around problems, with teachers ask questions and students solve problems through discussion. In the process of student discussion on problems, it is necessary to put forward their own views and work with other students in the discussion group to solve problems. Therefore, it requires students to have good language skills and cooperation capabilities. Due to the limited number of students in the student discussion group, it requires all students participate actively in the group discussion, which will inevitably exert restraint and control over student behavior. In the process of discussion, students' thinking ability, cooperative skill and language skills can be cultivated. Throughout the entire discussion process, teachers should play the role of organizational guidance, the intelligence of supervisory management, and the functions of behavior control to make teaching achieve the desired goals.

\section{The Principle of Data Mining Technology in Computer Education and Teaching}

The data mining process is to find that implicit and useful knowledge from a large amount of aggregated data. The basic steps are shown in Figure 2. Data mining technology is a new information processing technology, which has been widely applied in teaching management. The application of data mining to the teaching model of computer education, on the one hand, can promote the improvement, development and the necessary reform of the educational system. On the other hand, it can objectively reflect some problems in the teaching management of colleges and universities, provide important basis for formulating the policy and policy of the school, and further guide the students' enthusiasm for learning. Therefore, it will ultimately improve teaching quality and enhance teaching effectiveness. With the advancement of the process of education information, the application of data mining technology to education, and the discovery of hidden and useful knowledge from a large number of educational data to guide education and develop education has become an important research subject that is imperative.

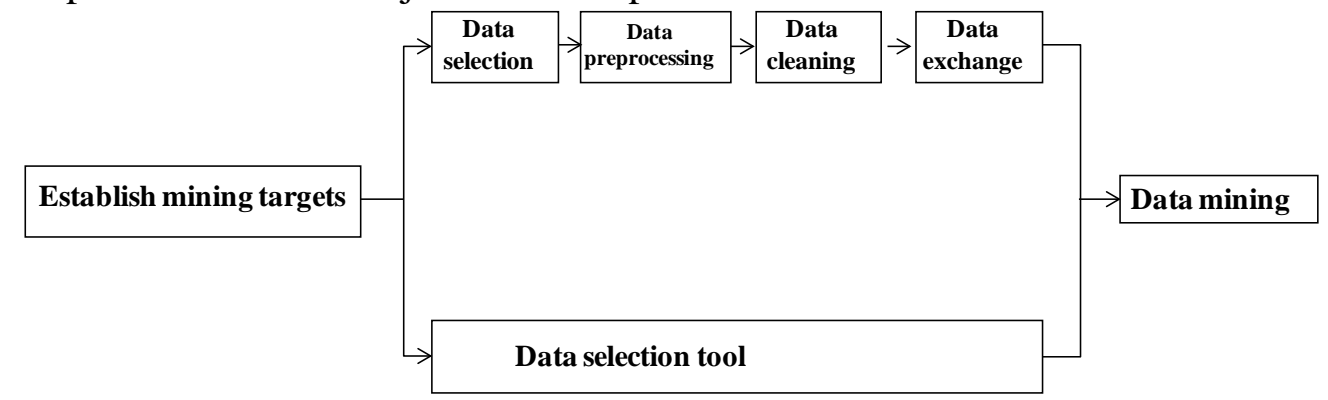

Fig.2 Data mining knowledge discovery process 
The teaching goal of the computer tutorial is to enable students to apply computer and information technology to their fields of work and become a composite talent who is familiar with both the professional business and the computer application technology.

Data mining involves artificial intelligence, databases, and statistics, in which the database's classification algorithm classifies other data of the same type, to provide guidance for the business system to have application value. As a widely used classification algorithm, the principle of decision tree is as follows: $A$ is the training data set, the entropy of $A$, which is the expected value formula, can be expressed as:

$$
\text { entropy }(A)=-\sum_{i=0}^{m} p_{i} \log _{2} p_{i}
$$

Where $m$ is the number of classes in the training data set, $B_{i}, i=1,2, \ldots m$ is the categories in the training data set, $\mathrm{C}_{\mathrm{i}}$ is the number of classes $\mathrm{B}_{\mathrm{i}}$, and $\mathrm{p}_{\mathrm{i}}$ is the probability that any data belongs to category $\mathrm{B}_{\mathrm{i}}$. The algorithm is simple and easy to implement, thus it has a strong guiding significance.

\section{The Application of Data Mining Technology in Computer Education and Teaching Reform}

\subsection{Application in teaching knowledge content}

There are scattered knowledge points in computer teaching, but there is also a close interdependence between knowledge points. Since learning is a gradual process, there are correlations and sequential relationships between knowledge points. The failure of a particular point of knowledge will affect the learning of subsequent points of knowledge. With the deepening of information technology in colleges and universities, many colleges and universities have begun to use the online teaching system. Research and development of various types of supplementary educational information platforms, their development and application have greatly improved work efficiency.

\subsection{Application in the performance analysis}

Data mining could be used to excavate the wrong question information in the online answer system, to help find the useful association rules, which will guide the teachers to find out the teaching loopholes and improve the teaching quality [3]. Experiments show that the proposed method can effectively find the correlation information between the various errors. The analysis of the test paper can use the association rules to analyze the test paper database to get the validity, credibility and score distribution of one specific test. It could also use data mining to analyze the scores of the students' previous examinations and their performance scores in the each part of papers, thus to analyze the progress of the students, the learning obstacles, the knowledge points and the mastery of the knowledge units, etc. These include the use of z-scores corresponding graphs to perform horizontal comparisons of student test scores for each subject at the same time, and the use of z-scores corresponding curve graphs and two columns of correlation coefficient analysis for longitudinal comparison of student scores in previous tests, and using the results distribution curve to draw the student's performance frequency distribution map. In teaching management, the commonly used data mining techniques are applied to various aspects such as teacher information, student information, and elective information to determine the degree of mastery of different knowledge points for students to understand student learning quickly and accurately. Besides, appropriate mining methods are used to explore hidden relationships among data and improve the level of teaching management so that teachers and school education decision makers can find the problems exist in teaching process.

\subsection{Application in teaching evaluation}

Data mining is a typical representative of computer technology, and its processing function for different data has been recognized by many users. With the application of computer technology in the 
modern education system, data mining technology has begun to be integrated into the testing and evaluation of computer capabilities, which has brought great convenience to the evaluation work and has been analyzed on the application of computer capacity assessment under data mining. The evaluation of teaching based on student assessment teachers has greatly promoted the teaching reform and the improvement of teaching quality.

Through data mining technology, the assessment of teachers' personal information, quality, and performance can be conducted. Data mining can be conducted from the teaching evaluation data, and various correlations between teaching effects and teachers' work attitude and work skills can be queried to find the teaching effect of teachers. With regard to the relationship between teacher performance and teacher performance, a class teacher can be allocated to a reasonable level so that the student can maintain a good learning status, which provides decision-making support information for the teaching department, and promotes better teaching and improves teaching quality. Based on the research of association rules mining algorithm, the author analyzes in detail the influence of teacher factors on students' test scores and students' evaluation of teaching results. The results show that teachers with rich teaching experience and good sense of responsibility can help students achieve good academic performance.

\subsection{Application in cultivating students' interest of learning}

Clustering analysis is to divide a set of data into several categories based on their similarity and difference. The purpose is to make of the data that belonging to the same category have the same similarity as much as possible, and the similarity of the data belong to the different categories is as small as possible [4]. Students are classified into different types by clustering techniques. The first type is the students who do not often surf the Internet and only do this several times occasionally. For this type of students, who do not often use information technology to assist computer-based learning, are not very interested in the computer infrastructure. The second type is for the students whom are not access to the internet frequently, but believe that the computer foundation is very useful for their learning and life. Such students ask for improvement of the traditional methods of computer-based teaching, and they believe that it is necessary for the establishment of collaborative learning group, and the use of task-driven teaching is very helpful for their learning.

\section{Summary}

The reform of computer education teaching model based on data mining is conducive to solving the problems faced by computer basic education, and can recommend personalized learning programs to find the right direction for students' autonomous learning. By collecting a large amount of learning data and analyzing and mining these data, it extends classroom teaching, provides effective guidance and decision-making information for teachers' individualized teaching, and provides powerful data support for students' professional orientation and individualized development. The promotion of the data-mining education and teaching model will open a new chapter for computer education and teaching.

\section{References}

[1] Zhu Ming. Data Mining [M]. Hefei: University of Science and Technology of China Press, 2012, p.19

[2] Ming Ye, Chen Jingliang. Research on Big Data Driven Model for Computer Basic Education[J], 2014(15), p.23

[3] Qi Zhigang, Jin Xu. Research and Implementation of Data Preprocessing in Data Mining[J]. Application Research of Computers, 2004(7), p.17

[4] Zeng Feifei. Research and Practice on University Computer Information Literacy Cultivation of University Computer Inquiry Teaching Model [D]. Changsha: Hunan Normal University, 2007, p.42 